\title{
Evaluation of early-age performance of reinforced concrete pile cap
}

\author{
Petr ŠTEMBERK*, Michaela FRANTOVÁ**, Martin PETř́́K*** \\ *Czech Technical University, Thákurova 7, Prague 6, 166 29, Czech Republic, E-mail: stemberk@fsv.cvut.cz \\ **Czech Technical University, Thákurova 7, Prague 6, 166 29, Czech Republic, E-mail: michaela.frantova@fsv.cvut.cz. \\ ***Czech Technical University, Thákurova 7, Prague 6, 166 29, Czech Republic, E-mail: martin.petrik@fsv.cvut.cz \\ cross $^{\text {ref }}$ http://dx.doi.org/10.5755/j01.mech.23.3.18479
}

\section{Introduction}

One of the easiest ways of acceleration of concrete production is the precast technology. The precast elements are usually produced in large amount, which makes this technology cost-efficient, but there are some limitations when irregular shapes or conditions occur. Therefore, some members, such as substructures and supporting members, still require the use of the conventional cast-in-place method, causing a bottleneck in schedule planning. One of the effective solutions to overcome this problem is to reduce the waiting time for concrete strength development by either early formwork removal or early loading on such members. The acceleration needs to comply with some specifications, such as, ACI 318-08 [1], however, this document does not specify when to remove the formwork, how to determine the earliest possible loading, and leaves this solely up to the contractor's decision. The greatest challenge then is to find the earliest possible instant for either formwork removal or application of the load so that the structural member is not damaged, especially when it is designed with consideration of its standardized compressive strength at 28 days.

The method of the structural analysis of the earlyage performance then becomes the key tool for identification of the earliest possible age for loading or formwork removal which regularly are the investors or, in the case of public project, government authorities. For infrequent planning, it would be impractical and computationally expensive to execute numerical analyses such those based on the finite elements. Then, a simple method that can be done even by less experience engineers but yet accurate enough is the objective of this study. Based on these reasons, this study proposes an evaluation method and numerical examples for the possibility of accelerated construction by early formwork removal and early loading of concrete members. To decide whether to accelerate the construction or not, it is required to determine the early age strength and stiffness of the members. The proposed method consists of three steps: 1) Selection of time-dependent development properties, 2) Structural analysis by Strut-and-Tie Model, and 3) Evaluation of developing performances of the members.

The proposed method is demonstrated on a numerical example for the case of a pile cap. Engineers may apply this method to more complicated cases. In the example, the structural analysis uses the STM approach performed with the Computer-Aided-Strut-and-Tie (CAST). CAST is an application for STM analysis developed by Kuchma [6]. Besides, a numerical analysis by SCIA Engineer [7] was performed and compared with the strut-and-tie model. The evaluations for capacity and deflection of the members in the early age are also established.

\section{Proposed method}

The mechanical performance of concrete at early age changes significantly and thus affect the early-age performance of structural members. For our case, the development of compressive strength, modulus of elasticity over time, and creep of concrete are in the focus. Those are limiting factors for the early formwork removal and loading in cast-in-place concrete construction. The effect varies with mix proportion, ambient temperature and curing conditions. Choosing some of the available material models provided by codes, or proposed by researchers could be an option when accurate information is not available. Then, the civil engineers and designers can have general ideas about timedependent behaviour of concrete from basic information, such as the design compressive strength.

Various material models from design codes and research regarding these effects are briefly reviewed below and the most applicable codes are shown. Only the dominant mechanical parameters are dealt with here, which are the compressive strength, the modulus of elasticity and the creep coefficient.

\subsection{Compressive strength and modulus of elasticity}

The compressive strength and the modulus of elasticity increase as a function of age of concrete and are affected by various factors, i.e., type of cementitious materials, type and amount of admixtures, water-to-cement ratio and ambient temperature during casting and curing period. Eurocode 2 [3] defines the compressive strength of concrete at various ages $\left(f_{c}(t)\right)$ depending on the mean compressive strength at 28 days $\left(f_{c m}\right)$ and the type of cement. It assumes a mean temperature of $20^{\circ} \mathrm{C}$ and curing in accordance with EN 12390-2 [8]. The modulus of elasticity at various ages $\left(E_{c}(t)\right)$ can be estimated from the mean elastic modulus at 28 days $\left(E_{c m}\right), f_{c}(t)$, and $f_{c m}$. The increment is an exponential function. fib MC2010 [4] has almost similar expression as Eurocode 2, except for the power of $\beta_{c c}(t)$ in the $E_{c}(t)$ model. The relationship between $E_{c}$ and time was based on the test results on CEM I and CEM II cement. Higher content of fly ash, natural pozzolans or blast furnace slag in concrete may reduce development of $f_{c}(t)$ at early age and increase at higher age [4]. The compressive strength development of JSCE2007 [5] and ACI 209.2R-92 [9] are closely related with changes in constants depending on type of cement ( $a$, $b$ and $d$ ). This adjustment may come from different characteristics between American and Japanese cement. However, different equations for $E_{c}(t)$ can be found. For both design codes, $f_{c}(t)$ and $E_{c}(t)$ may be estimated from $f_{c m}$ and type of cement.

The curves given by the selected design codes [1, 
$3,4,5]$ for predicting the compressive strength development of concrete having $f_{c m} 50 \mathrm{MPa}$ for various cements are illustrated in Fig. 1. All curves correspond to the assumed mean temperature of $20^{\circ} \mathrm{C}$, moist curing.

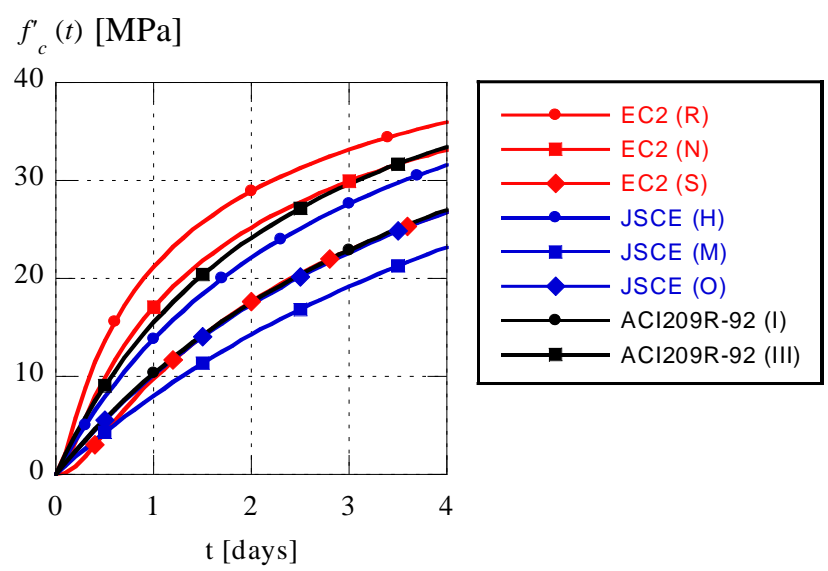

Fig. 1 Overview of codes for predicting $f_{c}(t)$ of concrete with $f_{c m}=50 \mathrm{MPa}$ in early age for various cement $(f i b$ MC2010 is the same as EC2)

The development of the modulus of elasticity predicted by the design codes for ordinary cement concrete with $f_{c m} 50 \mathrm{MPa}$ at early age is shown in Fig. 2.

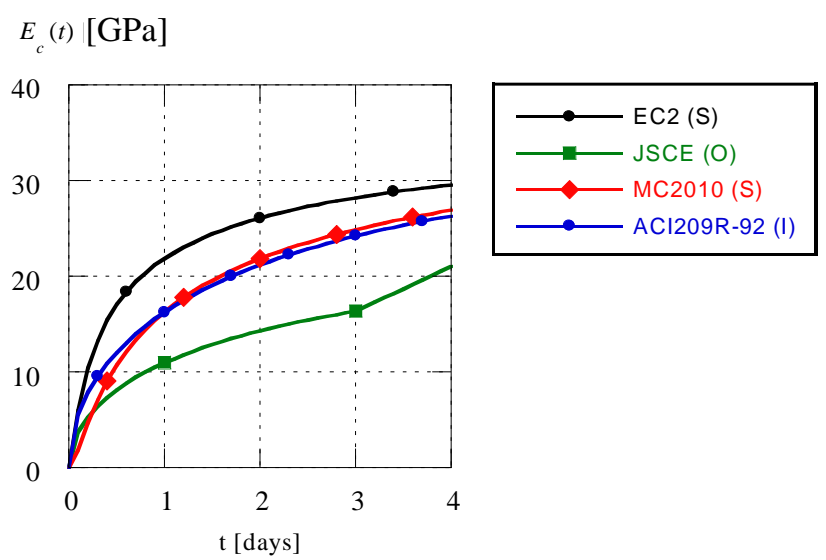

Fig. 2 Overview of codes for predicting $E_{c}(t)$ of ordinary cement concrete with $f_{c m}=50 \mathrm{MPa}$ at early age

\subsection{Creep coefficient}

Several models are available for prediction of the creep coefficient which have been adopted into design codes. The models require basic information of concrete such as duration of loading, compressive strength, ambient relative humidity $(R H)$, age at loading $\left(t_{0}\right)$, cement type and volume-surface ratio $(V / S)$, depending on the models.

It is worth mentioning the models for the creep coefficients in America (ACI 209.2R-92 [9]), in Europe (Eurocode 2 [2], CEB MC90-99 [10], fib MC2010 [4]) and in Japan (JSCE 2007 [5]). ACI 209.2R-92 [9] is an empirical model with a hyperbolic curve approaching an asymptotic value for predicting the creep coefficient at any time. The model is simple for concrete under 'standard conditions' as specified by the code. For other conditions, correction factors can be calculated from specific data that is cement type, curing type, $t_{0}, R H$, and volume-surface ratio. The creep coefficient model in Eurocode 2 is similar to CEB MC90-99
[10] model with different threshold of creep non-linearity. The JSCE2007 model [5] is also an empirical equation taking into account the mix proportion (water-cement ratio), $t_{0}$, age at beginning of drying $\left(t_{1}\right), E_{c}\left(t_{0}\right), R H$ and $V / S$. The model is intended for concrete with ordinary Portland cement; however, the effect of cement type on creep is reported in [5] to be relatively small and JSCE2007 model can be extended to high-early strength cement. A separate equation for concrete with $f_{c m}=55-80 \mathrm{MPa}$ is provided.

These models are rather complex and not so convenient for engineers who are less specialized in creep. In cases when a great accuracy is not necessary, Eurocode 2 [3] provides charts for determining the creep coefficient from $t_{0}$, notional size $\left(h_{0}=2 A_{c} / u\right.$, where $A_{c}$ and $u$ are the area and the perimeter in contact with atmosphere), concrete class, cement type, and $R H(50 \%$ and $80 \%)$ for concrete under the normal environmental condition at time $t=\infty$. With the similar input as Eurocode 2, fib MC2010 [4] provides two separate tables for the creep coefficient of a normal strength concrete and a high strength concrete after 50 years of loading. It was reported that creep between 50 years to 150 years increases less than $10 \%$ of creep after 50 years. In JSCE 2007 [5], where the mix proportion is still unknown, the creep coefficient for 'normal members' as specified by the code and the members with $1 \%$ reinforcement ratio, can be taken from tables provided in the code. The applicability of these prediction models are limited to some certain conditions, which vary from code to code. The concrete subjected to extreme environments is usually not covered.

\subsection{Structural analysis by Strut-and-tie model}

The STM approach is implemented in various design codes, specifications, and recommendations for bridges and buildings [1, 3-5]. It is a simplified approach but yet accurate for the design of members in D-region. The force path in the members is converted, in accordance with the equilibrium within the members, into a system of concrete compressive struts and reinforcement tension ties. The design is performed by determining the necessary capacity of its members and nodes. Worked design examples for STM are available in [11]. The application of STM to various cases, e.g., eccentric columns, hammerhead piers, or pile caps, can be found in [2]. The capacity of reinforcement tie is taken as the multiplication of the reinforcement cross-sectional area and the design yield strength $\left(A_{s} f_{y d}\right)$, which is straightforward and consistent in various codes. The predicted strength of the concrete compressive struts is somewhat ambiguous. In general, the transverse tension in compressive struts tends to weaken their capacity.

\subsection{Evaluation of developing load-bearing capacity}

In order to determine the possibility to accelerate the construction process by early formwork removal and early loading of concrete members, the development of mechanical performance of the structural members need to be evaluated. Based on the review summarized above, engineers may decide to follow the appropriate recommendation of their choices, according to their requirements and limitations. The capacity of the members at early age is usually limited by the strength of the concrete strut. The limitation of applied load at an age $t$ may be calculated from the ge- 
ometry of the Strut-and-Tie Model. Consequently, the deflection or deformation of the members at the age $t$ are needed to be checked since the stiffness of members are comparatively low at early age. The total deflection may be assumed as the summation of instantaneous strain at loading and creep strain. A material model for evaluating instantaneous and time-dependent strain of concrete subjected to uniaxial short-time and sustained load at very early ages was proposed by Štemberk and Kalafutová [12]. It should be noted that long-term creep effect may increase due to early loading. The relationship for the limitation of the applied load to the members with respect to strength and stiffness and time may be drawn for easy and flexible decision making.

\section{Numerical example of pile cap}

Due to usual ground conditions, pile caps are generally cast in place, while the other connected structural members, such as the piles and the columns, can be prefabricated in factories. Evaluation of the pile cap capacity at early age is a crucial factor for acceleration of construction.

In the case of elevated roads or railways, accelerated construction is required in order to minimize public and traffic interference. Many construction techniques are being used today, including the precast segmental method. Superstructures are precast segments while piers or columns may be precast or cast-in-place. depending on the project.

In this numerical example, a case of four-pile cap having dimensions of $5.0 \times 5.0 \times 1.5 \mathrm{~m}$ is considered, as shown in Fig. 3. The pile cap is made of concrete of strength class C35/45 with rapid hardening portland cement I 42.5 R. The concrete mixture is composed of: water $180 \mathrm{~kg} / \mathrm{m}^{3}$, cement $430 \mathrm{~kg} / \mathrm{m}^{3}$, sand $780 \mathrm{~kg} / \mathrm{m}^{3}$, fine aggregate $140 \mathrm{~kg} / \mathrm{m}^{3}$, and coarse aggregate $965 \mathrm{~kg} / \mathrm{m}^{3}$. The ambient temperature is considered as $20^{\circ} \mathrm{C}$ during the hydration process. The pile cap is subjected to an axial load of $48000 \mathrm{kN}$ from a square $2.0 \times 2.0 \mathrm{~m}$ column. The construction is assumed to be in the US and is supposed to follow ACI Codes [1,9].

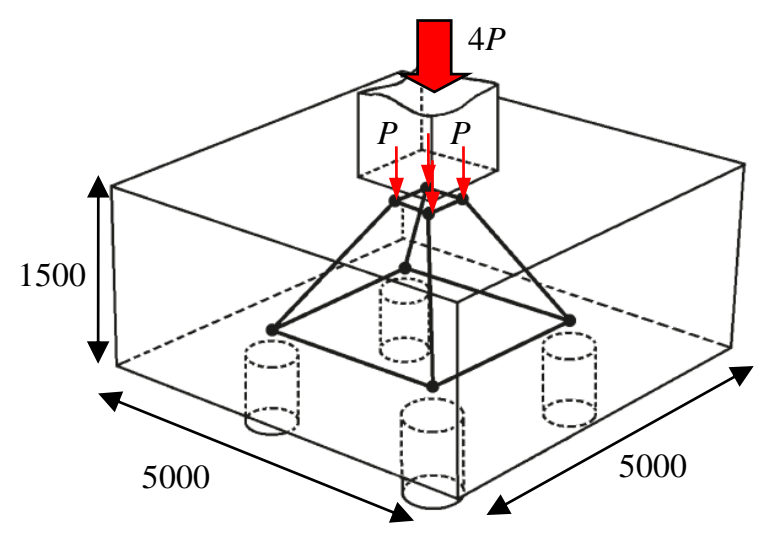

Fig. 3 Simplified STM model for the pile cap

In the selection of material properties, moderate heat cement is generally required in the mass concrete casting process, such as for pile caps, however, ACI209R-92 model does not provide such case. Considering similarity in ACI209R-92 and JSCE2007 models for $f_{c}(t)$, the mathematical model for moderate heat cement by JSCE2007 can be used instead, which hints on the common practice in the design offices.

The application of STM for prediction of the loadbearing capacity of four-pile caps is explained as follows. The axial load from the column was divided evenly into four concentrated loads acting on the pile cap. A simplified three-dimensional force path for the case of four-pile cap is illustrated in Fig. 3. Because of symmetry, the pile cap was considered as a two-dimensional STM model with half

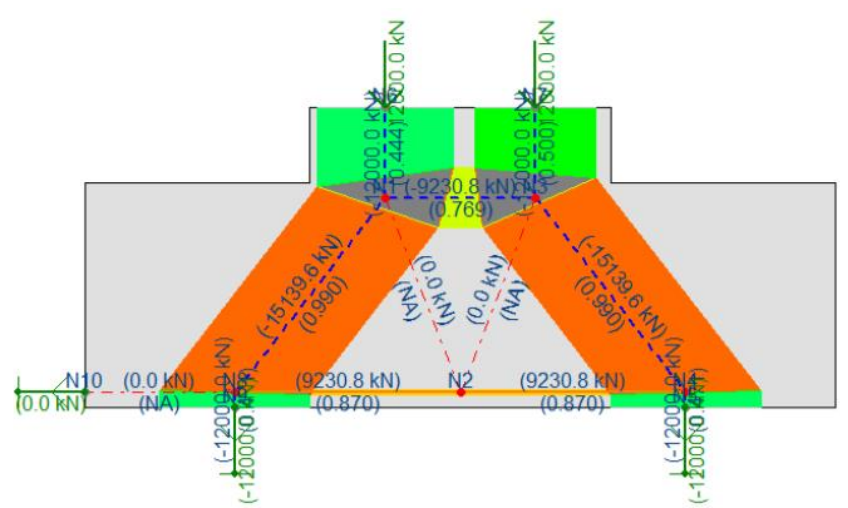

Fig. 4 Detailed results of STM for the pile cap

thickness in this study. The reinforcement bars were assumed as $25 \varnothing 36\left(f_{y}=450 \mathrm{MPa}\right)$. The prismatic concrete compressive struts were assigned to all struts except for the inclined struts, to which the bottle-shaped strut was assigned. The width of the compressive strut was assumed to be $800 \mathrm{~mm}$, which corresponds to the diameter of the pile. The results of STM performed by CAST is shown in Fig. 4. The critical members are the inclined compressive struts. The limition of the load to be applied on the pile caps is governed by the inclined compressive struts, thus $P_{u}(t)$.

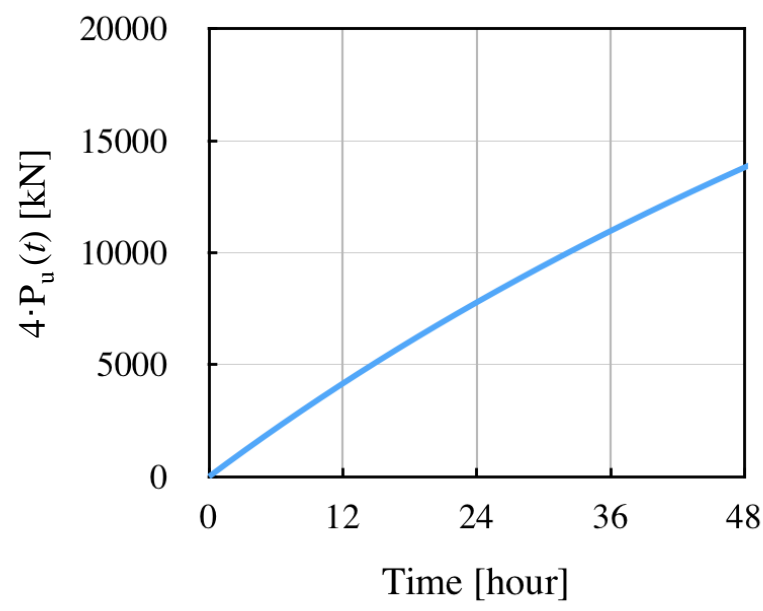

Fig. 5 Capacity of the pile cap developing over time

Fig. 3 then shows the relationship between the maximum allowable load $4 P_{u}(t)$ and the age of concrete $t$ (hours) of the pile cap during the first 48 hours. Fig. 5 can also serve as a flexible guideline for assessing the maximum construction loads on the pile cap upon which the decision on accelerating the construction can be made. 


\section{Conclusions}

The scientific results often serve as the bases for another research and hardly are readily applicable. The complexity of the findings usually requires development of complex software which eventually serving as a black-box tool forces the structural designers into already predefined solutions, often favouring some entities on the construction market. On the contrary, this study tried to provide the civil engineers with a simple tool, which addresses today's most common issue which is acceleration of construction. But, in turn it can be used for quick rough verification of the complex software results.

In order to develop a simple evaluation method for identifying the earliest possible instant for formwork removal or premature loading, the latest construction standards were reviewed and the relevant regulations were studied. This was because the construction must follow these standards anyway. The studied factors were the compressive strength development, stiffness development and the creep effects. The structural analysis method was then selected to be based on the strut-and-tie model approach, which is straightforward and fully understandable to any engineer. Since the function defining the strength, stiffness and creep development are taken from the codes and the strut-and-tie modelling is also recommended by codes, the proposed evaluation method can be readily used on the daily basis.

The study provided a procedure for fast decision regarding formwork removal and premature loading. The primary applicability is in the common practice where complex finite element analyses are usually impractical and even dangerous when the necessity of a large amount of often unknown parameters is taken into account. Here, the advantage of the proposed method is its simplicity, which was demonstrated in an example of the most common bottleneck in the construction process, which is the cast-in-place reinforced concrete pile cap. The result shows the curve which defines the development of the maximum load permissible at given age of concrete (counted from the instant when water touches cement in the mixer). Such result is the basis for decision-making about the possible acceleration of removal of formwork or placing other structural members on the pile cap. Anther field of application is in development of complex numerical analyses where the results can be quickly verified.

\section{Acknowledgements}

This work was financially supported by the Czech Science Foundation, project 16-20008S, and the Czech Technical University in Prague (CTU), project SGS17/048/OHK1/1T/11, which are gratefully acknowledged.

\section{References}

1. ACI Committee 318. 2008. Building Code Requirements for Structural Concrete (ACI 318M-08) and Commentary. American Concrete Institute.

2. Frantová, M.; Štemberk, P; Vala, V. 2011. Application of Strut-and-Tie Model on Eccentric Columns. Mechanika 17(2): 126-131. http://dx.doi.org/10.5755/j01.mech.17.2.326.
3. EC2. 2004. Eurocode 2. Design of Concrete Structures. Part 1-1. General Rules and Rules for buildings. EN 1992-1-1. European Committee for Standardization.

4. fib. 2012. Model Code 2010 for Concrete Structures. International Federation for Structural Concrete: Ernst and Son.

5. JSCE Concrete Committee. 2010. JSCE Standard Specifications for Concrete Structures. 2007. Design.

6. Kuchma, D.; Tjhin, T. 2001. CAST (Computer-Aided Strut-and-Tie) Design Tool. Structures 2001: 1-7. http://dx.doi.org/10.1061/40558(2001)142.

7. SCIA Engineer. Nemetschek.

8. EN 12390-2. 2012. Testing Hardened Concrete. Part 2. Making and Curing Specimens for Strength Tests. EN 12390-2:2012. European Committee for Standardization.

9. ACI Committee 209. 1992. Prediction of Creep, Shrinkage, and Temperature Effects in Concrete Structures (ACI-209R-92). American Concrete Institute: 47.

10. CEB. 1999. Structural Concrete-Textbook on Behavior, Design and Performances. Updated Knowledge of the CEB/FIP Model Code 1990. fib Bulletin 2(2): 37-52.

11. Reineck, K.H. 2002. Examples for the Design of Structural Concrete with Strut-and-Tie Models. ACI International SP-208. 262p.

12. Štemberk, P; Kalafutová, P. 2008. Modeling very early age concrete under uniaxial short-time and sustained loading. Mechanika 2(70): 16-21.

Petr ŠTEMBERK, Michaela FRANTOVÁ, Martin PETŘíK

\section{EVALUATION OF EARLY-AGE PERFORMANCE OF REINFORCED CONCRETE PILE CAP}

\section{S u m m a r y}

The acceleration of construction in terms of early formwork removal or premature loading has a critical effect on the total construction cost. In order to perform the acceleration correctly, good decisions must be made. This paper provides a simple structural analysis method based on the strut-and-tie modelling which helps to make such decisions. The strength and stiffness development of concrete at early age is reviewed in the most relevant construction codes and the most suitable formulations are recommended. Then, the strength and stiffness development functions are introduced into the strut-and-tie model and the two-dimensional or three-dimensional structural analysis can be performed. The effect of creep is also included in terms of the creep coefficient so that the long-term consequences of the accelerated construction can be also evaluated. The proposed method is demonstrated in an example of a reinforced concrete pile cap. The method is useful either for engineering practice or for a quick rough verification of complex numerical simulations of hardening concrete when prematurely loaded.

Keywords: accelerated concrete construction, early formwork removal, pile cap, strut-and-tie model, time-dependent development.

Received January 20, 2017

Accepted June 08,2017 